\title{
Study of the physico-chemical properties of recycled polymers from waste electrical and electronic equipment (WEEE) sorted by high resolution near infrared devices
}

\author{
Joana Beigbeder ${ }^{\mathrm{a}, *}$, Didier Perrin ${ }^{\mathrm{b}}$, Jean-François Mascaro ${ }^{\mathrm{c}}$, José-Marie Lopez-Cuesta ${ }^{\mathrm{b}}$ \\ a Ecole des Mines d'Alès CMGD, Hélioparc 2, Avenue P. Angot, 64053 Pau Cedex 9, France \\ b Ecole des Mines d'Alès CMGD, 6, avenue de Clavières, 30319 Alès Cedex, France \\ ${ }^{\text {c } P E L L E N C ~ S T, ~} 125$ rue François Gernelle, BP 124, 84124 Pertuis Cedex 4, France
}

\begin{abstract}
A B S T R A C T
Recycling of plastics from waste electrical and electronic equipment (WEEE) requires large scale high-performance sorting and identification technologies. The aim of this project is to evaluate the sorting performances of near infrared (NIR) devices, developed by the company PELLENC ST, for three styrenic polymers from WEEE: acrylonitrile-butadiene-styrene (ABS), high-impact polystyrene (HIPS) and $\mathrm{ABS} /$ polycarbonate blend $(\mathrm{ABS} / \mathrm{PC}$ ) and to study the physico-chemical properties of recycled materials. The use of an improved near infrared technique allows high levels of efficiency and performance to be achieved. This study can be used to evaluate the substitution ratio of virgin styrenic polymers by recycled ones for life cycle assessments (LCA) of reclaimed materials. Mechanical properties and fire properties of the sorted polymers were investigated. Mechanical properties of the polymers, particularly these of HIPS, were slightly modified after sorting. However, a degradation of the polybutadiene phase was observed. Fire tests revealed the presence of flame retardants in ABS and HIPS. Hence, NIR process could be used after a first sorting of brominated plastic wastes, in order to respect the RoHS directive. This project offers industrially viable alternatives for the recovery of plastics waste and the use of secondary raw materials.
\end{abstract}

\section{Introduction}

Electronic industry has lived several technological revolutions these last decades. The constant evolution of technologies coupled with a planned obsolescence of products leads to a huge amount of waste electrical and electronic equipment (WEEE). WEEE generated in the European Union was appraised at around 9 million tonnes per year in 2005 (Huisman et al., 2007). A recent report of the UNEP has estimated a tremendous increase of electronic waste for developing countries: by 2020, WEEE in South Africa and China will have soared to 200-400 per cent from 2007 levels and to 500 per cent in India (UNEP, 2009). Illegal exportation of WEEE to developing countries, especially Africa and China, has been pointed out by several nongovernmental organizations (Puckett et al., 2003; Hosoda, 2007; SBC, 2011).

To limit this exponential growth of EEE wastes, the European Commission adopted in 2002 the Directive 2002/96/EC on

\footnotetext{
* Corresponding author. Tel.: +33 559309994.

E-mail addresses: joana.beigbeder@mines-ales.fr, joana.beigbeder@gmail.com (J. Beigbeder)
}

WEEE which defines strict recycling quotas on 10 WEEE categories (European Commission, 2003a). Quotas imposed are ambitious: $50-75 \%$ for recycling rates and $70-80 \%$ for recovery rates.

With an average polymer content of about $30 \mathrm{wt} \%$ in WEEE (Menad et al., 1998; Taurino et al., 2010), recycling and waste recovery of plastics from WEEE is a key issue to achieve directive quotas. There are several strategies to recycle plastics and thus to avoid landfilling (Vilaplana and Karlsson, 2008). Using mechanical recycling, a secondary raw material is produced from plastic waste through processes based on physical phenomena. Feedstock recycling consists in cracking and depolymerizing plastic waste to obtain a series of petrochemical products or monomers (Aguado et al., 2006; Garforth et al., 2004). Energy recovery enables to produce energy through incineration processes of plastic wastes, thanks to their high calorific content (Mirza, 1999). Others recycling processes, such as chemical recycling, can solubilize both thermoplastics and a few fraction of thermosets polymers (i.e. sheet moulding compounds) by solvolysis (Perrin et al., 2006).

Life cycle assessment (LCA) is a standardized method used to evaluate the environmental impacts of a product or a service (ISO 14040). Many studies deal with LCA of plastic wastes recycling (Jenseit et al., 2003; Perugini et al., 2005; Shonfield, 2008; 
Finnveden et al., 2005). Most of time, they compare the different routes used: energy recovery, mechanical, chemical, feedstock recycling or landfilling for thermoplastics polymers, which represent $80 \%$ of total plastic consumption (Al-Salem et al., 2009). Results vary strongly according to the selected route. For Salem et al. feedstock recycling is the most sustainable solution as it recovers valuable petrochemicals while producing energy (heat, steam, etc.). They emphasize the disadvantages of mechanical recycling as the necessity to obtain a high quality, clear, clean and homogenous recycled material to compete with virgin polymer or the degradation of polymers chains occurring during re-processing. Lazarevic et al. has reviewed LCA of plastic waste recycling and they conclude that mechanical recycling is generally the environmentally preferred treatment option (Lazarevic et al., 2010). However, they specified that some critical parameters can reverse the trend, especially the organic contamination content and the virgin material substitution ratio. Indeed, this organic contamination engenders an additional step of washing, inducing a waste water treatment, whereas the organic content increases the heating value of the waste and thus favours the energy recovery option (Frees, 2002). The virgin material substitution ratio, defined as the ratio at which recycled plastic substitutes virgin plastic at equivalent properties, is essential to evaluate the ecological impacts. Indeed, when recycled plastic has a lower quality than virgin one, a mix with the virgin polymer is considered in order to lead to a recycled material with the same properties than virgin one, and thus environmental impacts linked to the virgin polymer production and transport are included in the LCA. When it is lower than 0.5, the benefit of mechanical recycling compared to incineration is less evident (Lazarevic et al., 2010). It can be noticed that in most of studies the substitution ratio is assumed to be 1 , by lack of data about recycled polymers. Quality of recycled polymer is directly linked to purity. Thus, to ensure environmental and economic benefits, purity of recycled polymers must be the highest possible, a level of $5 \mathrm{wt} \%$ is acceptable whether the polymer considered. A complete study of the Waste and Resources Action Programme (WRAP) (Shonfield, 2008) about the LCA of management options for mixed waste plastics compared different scenarios of recycling with different technologies. They concluded that landfilling and incineration were the worst options. They also noted that the substitution ratio was a critical point to ensure the benefit of the mechanical recycling. LCA for waste plastic management is difficult to perform due to the lack of data about recycled polymers properties. Thus, it is essential to evaluate substitution ratios, which are directly linked to the sorting process.

Moreover, the interest of the mechanical recycling of thermoplastics is limited due to the quality of the recycled material. Thermoplastics polymers show only a limited compatibility among each other. Hence, contaminated fractions and mix of different polymers lead to a drastic decrease in the plastic properties and thereby entail limited applications for the recycled material. Then, to recover mixed thermoplastics waste, mechanical properties have to be improved by adding additives such as impact modifiers (Elmaghor et al., 2004) or by mixing recycled polymers with virgin ones (Mehat and Kamaruddin, 2011). Mechanical recycling can only be viable if the recycled polymers can compete, technically and economically, with virgin ones.

To preserve environment, the use of some hazardous substances is restricted by the RoHS European Directive (2002/95/CE European Commission, 2003b). Since 2006, EU members' states have to ensure that all new electric and electronic devices do not contain lead $(\mathrm{Pb})$, mercury $(\mathrm{Hg})$, cadmium $(\mathrm{Cd})$, hexavalent chromium $(\mathrm{Cr}$ $(\mathrm{VI})$ ), and four brominated flame retardants. Most of plastics from WEEE contain contaminants as heavy metals or brominated flame retardants (BFRs), mainly polybrominated diphenylether (PBDE). BFRs are widely used to improve the fire reaction of polymers. By thermal degradation, those contaminants are suspected of promote the production of highly toxic compounds, such as halogenated dioxins and furans (Ebert and Bahadir, 2003). Consequently, an essential step to WEEE plastics recycling is the separation of flame-retarded plastics fraction containing halogens from the other plastics, to exclude them from the recycling loop.

Engineering polymers such as acrylonitrile-butadiene-styrene (ABS), high impact polystyrene (HIPS) and polycarbonate (PC)/ABS blends, constitute around $50 \mathrm{wt} \%$ of the recovered plastics of endof-life electronics. ABS consists of styrene-acrylonitrile copolymer (SAN) mixed with a polybutadiene (PB) rubber phase. PB particles are generally grafted with acrylonitrile and/or styrene to improve the adhesion with SAN matrix (Xu et al., 2005). Chemical and heat resistance, toughness, rigidity and easy processing are provided by SAN while PB provides impact strength. HIPS is a mix of polystyrene (PS) and $\mathrm{PB}$, which improves the impact strength properties of PS. PC main features are high impact resistance and good fire behaviour, despite it is relatively expensive and very notch sensitive. To improve PC properties, it is often mixed with ABS to obtain PC/ABS blends which combines the good mechanical and thermal properties of PC and the ease of processability, notched impact resistance and the sometimes lower price of ABS. ABS content is generally around $25-30 \mathrm{wt} \%$. Mechanical properties of ABS and HIPS, especially impact properties, are highly dependent on the PB particle size and volume fraction (Bucknall et al., 1986).

To separate mixed plastics, technologies based on different polymer's properties are used, like density (Ferrara and Meloy, 1999; Pongstabodee et al., 2007), electromagnetic (Dodbiba et al., 2005) or surface properties (Shibata et al., 1996; Buchan and Yarar, 1995). However, those techniques do not permit to separate polymers of the same family, since densities are too similar, or polymers charged with an important level of additives, since densities are too modified. For instance, Shen et al., were not able to distinguish ABS from PS by flotation with several surfactants (Shen et al., 2002). Thus, a direct identification of the polymers nature is more reliable, in order to sort them automatically from a waste flow. Several techniques can be used to identify polymers and additives: mass spectroscopy (Luederwald, 1981), X-ray fluorescence (Boeykens and Vázquez, 2004), plasma spectroscopy (Anzano et al., 2010), vibrational spectroscopy as infrared spectroscopy (Weyer, 1985; Bledzki and Nowaczek, 1994; Taurino et al., 2010) or Raman spectroscopy (Florestan et al., 1994; Mailhot and Gardette, 1996). Near infrared spectroscopy of polymers is influenced by additives presence, whether their chemical structures, concentrations and thus infrared absorbance. Indeed, this technology has been used to quantitatively measure some additives concentrations (Solera et al., 1999; Karstang and Henriksen, 1992). However, a characteristic spectrum is measured for each polymer and then identification is possible even with additives, except black carbon.

Infrared spectroscopy is a relevant method for automatic sorting of polymers as it is a non-destructive and fast technique. Both the near-infrared (NIR) (wavelengths between $0.8 \mu \mathrm{m}$ and $2.5 \mu \mathrm{m})$ and mid-infrared (MIR) ranges $(2.5-30 \mu \mathrm{m})$ can be used for spectroscopic analysis of physical and chemical polymeric properties. NIR spectroscopy is more adapted than MIR to automatic sorting as spectrum acquisition is faster (Huth-Fehre et al., 1995; Wahab et al., 2006). The accessibility of NIR sensors led to the development of this technique. NIR spectroscopy presents a lot of advantages: remote high speed measurements, high penetration depth of the NIR radiations, which prevents a sample pre-treatment, and an important signal-to-noise ratio. The main disadvantage of NIR spectroscopy is the incapacity to detect black polymers as radiation is totally absorbed by this kind of material. In addition, NIR photons excite two or more different molecular vibrations simultaneously, and then absorption is weaker and featureless than with MIR. Thus, to exploit NIR spectroscopy as a 
Table 1

Size of plastic flakes of the studied samples.

\begin{tabular}{llrrr}
\hline PW & Polymers & $s<10 \mathrm{~mm}$ & $10 \mathrm{~mm}<s<20 \mathrm{~mm}$ & \multicolumn{2}{c}{$s>20 \mathrm{~mm}(\mathrm{~kg})$} \\
\hline 1 & ABS, ABS/PC & $8 \%$ & $92 \%$ & $0 \%$ \\
2 & ABS, HIPS, PP, non plastic parts & $0 \%$ & $0 \%$ & $100 \%$ \\
3 & ABS, HIPS, ABS/PC, PVC, non plastic parts & $1 \%$ & 8.00 & $91 \%$ \\
\hline
\end{tabular}

fast, accurate, non-destructive and remote sensing identification technique, an indirect calibration of the spectra is necessary. This calibration consists in the measurement of a representative numbers of samples with the desired polymer composition. This step, called the machine learning, requires standard samples with known composition. NIR technique has already been studied to identify plastics, as polyethylene terephthalate (PET), polyvinyl chloride (PVC), polypropylene (PP), or polyethylene (PE), in household waste or building and construction waste (Serranti et al., 2012) and also for the more recent biobased polymer polylactid acid (PLA) (Ulrici et al., 2013). Classification of measured spectra can be carried out using an artificial neural network (Huth-Fehre et al., 1995; Scott and Waterland, 1995) or using classical techniques, such as linear discriminant analysis (DLA) and partial least square (PLS) (Van den Broek et al., 1998).

The aim of this paper is to present the sorting performances of automatic NIR sorting devices, developed by PELLENC ST Company, devoted to WEEE plastics and the properties of the sorted materials. Mechanical and fire properties of three of the sorted polymers: $A B S, H I P S$ and $A B S / P C$ were evaluated. The originality of this work consists in the study of polymer materials separated on line, as in industrial conditions, using near infrared spectroscopy as sorting technology. Results of mechanical properties can then be used to evaluate the substitution ratio for an LCA of plastics from WEEE sorted by NIR automating technology.

\section{Experimental}

\subsection{Sorting system}

\subsubsection{Materials}

Plastic waste (PW) samples of WEEE from different sources were used to test the sorting performances of NIR devices. For the device 1 , a mix of several plastic from differents WEEE sources was used. For the device 2, three distinct lots were studied: firstly, a reference lot: PW1, with only ABS and ABS/PC, was made by selecting already identified samples of $A B S$ and $A B S / P C$ from computer and information technology products. The nature of polymers of PW1 was identified with a MIR spectrophotometer (Bruker IFS 66 FTIR). The second one, PW2, corresponded to an actual waste deposit from household appliances such as fridges and stoves. It was mainly composed of ABS, HIPS and PP, but also of non-plastic materials such as metal and wood. A third lot, PW3, also from a waste deposit of computers was composed of "grey plastics": ABS, HIPS, ABS/PC, PVC and of a small part of non-plastic materials. Size of plastic flakes $(s)$ after grinding and weight of each lot are presented in Table 1 . The size of flakes was determined using sieves of $10 \mathrm{~mm}$ and $20 \mathrm{~mm}$. The weight content of each polymer differs in lots,

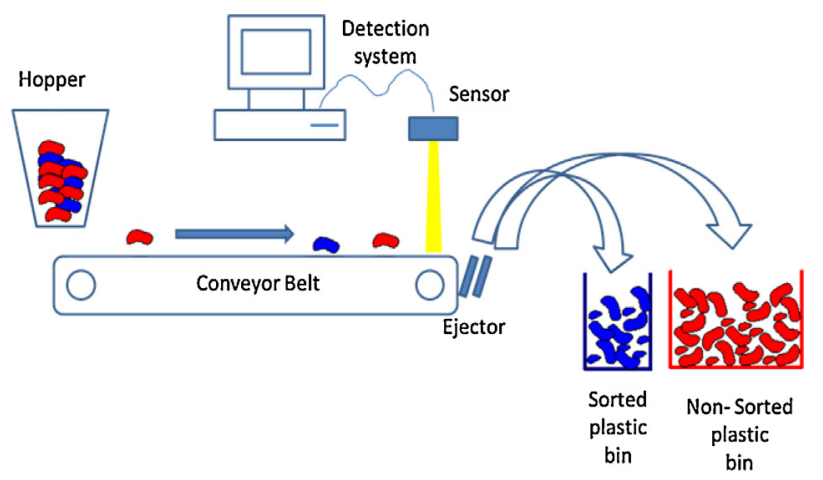

Fig. 1. Illustration of the automated sorting system.

with a predominance of styrenic polymers but also black polymers (Table 2).

\subsubsection{Sorting principle and characterization methods}

The high resolution near infrared (NIR) technology, called Mistral series, developed by PELLENC ST (Pertuis, France) aims to sort various kinds of materials on the range of $1000-2100 \mathrm{~nm}$. The spectrum of the objects located on a conveyor belt is obtained and the composition of each material is recognized. The detection system was developed by PELLENC ST, first, the machine learns the models spectra from standard samples, which define the reference database. Then each analyzed sample is compared to the models spectra. A specific mathematical treatment leads to the distance between the analyzed spectra and a model one, a minimal distance is needed to separate two polymers. An upgradeable software application allows the identification of new materials to be performed. Simultaneous recognition allows different plastics to be sorted from each other:

- Commodity plastics: PET, high density PE, low density PE, PP, PS, PVC.

- Engineering plastics: ABS, ABS/PVC, ABS/PC, HIPS, PC.

- Fibrous materials: elasthane, paper and cardboard.

The distance between the detection zone and the ejection is deliberately very close to avoid errors resulting from the trajectory of objects on the conveyor belt.

The main components of the sorting system are illustrated on Fig. 1. Samples are deposed on a conveyor by a hopper; they are transported under the NIR light and sensor and are ejected in the collecting bins if desired. The system permits to sort one plastic type only. The conveyor has a length of $4 \mathrm{~m}$ and a speed of $2.5 \mathrm{~m} / \mathrm{s}$. The absorption spectrum of each sample is acquired by a spectrometer

Table 2

Mass composition of each studied lot.

\begin{tabular}{lccccc}
\hline PW & ABS & ABS/PC & HiPS & Other polymers & Other material \\
\hline 1 & $63 \%$ & $37 \%$ & & & \\
2 & $39 \%$ & & $22 \%$ & $16 \%$ & $21 \%$ \\
3 & $40.3 \%$ & $14.4 \%$ & $2.6 \%$ & $2.4 \%$ & $31.2 \%$ \\
\hline
\end{tabular}


Table 3

Sorting system characteristics of device 1.

\begin{tabular}{ll}
\hline Work width & $500 \mathrm{~mm}$ \\
Conveyor speed & $1.5 \mathrm{~m} / \mathrm{s}$ \\
Capacity & $800-1000 \mathrm{~kg} / \mathrm{h}$ \\
Sorted polymers & ABS, ABS/PC, PVC, PC, HIPS \\
Dark or black samples & Non sorted \\
Size of analyzed samples & $10-20 \mathrm{~mm}$ \\
\hline
\end{tabular}

Table 4

Characteristics of the new device 2 .

\begin{tabular}{ll}
\hline Work width & $800 \mathrm{~mm}$ \\
Conveyor speed & $2.5 \mathrm{~m} / \mathrm{s}$ \\
Capacity & $2 \mathrm{t} / \mathrm{h}$ \\
Sorted polymers & 11 \\
Dark or black samples & Non sorted \\
Size of analyzed samples & $5-200 \mathrm{~mm}$ \\
\hline
\end{tabular}

and on line analysis is performed using a computer. Analysis time is typically around $40 \mu \mathrm{s}$.

The system learns the spectroscopic fingerprint of materials which have to be sorted: several samples having the same composition are analyzed; the spectrum obtained for each plastic type defines a model. This stage is essential to ensure a good sorting. The first material database (A) learned by the system is made of 5 types of plastic: ABS, ABS/PC, PVC, PC and HIPS. The characteristics of this basic system, noted 1 , are presented in Table 3 .

Performances of the sorting system are determined by means of two indicators: the removal efficiency and the purity. Removal efficiency is defined as the yield of the sorting; it is calculated as the ratio of the mass of a given sorted material to the initial total mass of this material. The purity of the sorting reveals the error of sorting it is defined as the ratio of the mass of desired sorted material to al materials sorted in the same bin. The nature of the sorted plastic samples was identified with a Bruker IFS 66 FTIR spectrophotometer. With PW3, a quartering process was first carried out to limit the number of analysis. A Perkin Elmer Diamond differential scanning calorimeter (DSC) was also used to determine the nature of impurities of the sorted plastic samples. $\mathrm{ABS}$ and $\mathrm{ABS} / \mathrm{PC}$ samples were heated from $20^{\circ} \mathrm{C}$ to $260^{\circ} \mathrm{C}$ at $10^{\circ} \mathrm{C} / \mathrm{min}$ under nitrogen atmosphere and kept at $260^{\circ} \mathrm{C}$ for $1 \mathrm{~min}$. The cooling ramp was similar. $\mathrm{X}$-ray diffraction was used to determine the presence of brominated flame retardants with a Bruker D8 diffractometer using CuKa radiation. Data were collected between 1 and $13^{\circ}$ by step of $0.02^{\circ}$ using an X-ray generator with $\lambda=0.15406 \mathrm{~nm}$.

\subsubsection{Improvement of the sorting system}

The sorting system was optimized to handle with large WEEE waste flows. Several modifications of the basic device 1 were made to lead to a new one (noted 2). Algorithms used to treat infrared spectra were the same for the two devices. The new characteristics are presented on Table 4. The detection system was highly improved in order to detect samples with a minimal size of $25 \mathrm{~mm}^{2}$ instead of $100 \mathrm{~mm}^{2}$ for the basic device. The acquisition frequency was increased: 2.5 more spectrums are analyzed for each run. The range of analysis of the NIR spectrometer was enlarged to better distinguish $A B S$ and HIPS. A new database (B) containing 11 polymers: ABS, ABS/PC, PVC, PC, HIPS, polyamide (PA), poly(phenylene oxide)(PPO)/PS, polyoxymethylene (POM), SAN, PC/PET, and acrylonitrile styrene acrylate (ASA)/PC, was set up in the system. These

Table 5

Notations of sorted samples.

\begin{tabular}{ll} 
Plastic 1A & Plastic sorted once with device 1 and database A \\
Plastic 2B & Plastic sorted once with device 2 and database B \\
Plastic $(2 \mathrm{~B})^{2}$ & Plastic sorted twice with device 2 and database B \\
\hline
\end{tabular}

plastics were selected according to the main plastics found in WEEE. The use of a material database (A or B) is independent of the device.

\subsection{Polymer recycling and testing}

\subsubsection{Materials}

The materials from PW3 sorted using both devices $(1,2)$ and both databases (A, B) were studied. Only PW3 was tested, because mass of lots PW1 and PW2 were not sufficient to realize test specimens. Three polymers were sorted: ABS, ABS/PC, and HIPS with a total mass of $4 \mathrm{~kg}$ for each sorting process. Those polymers were chosen because of their predominance in WEEE plastic wastes. After sorting, each fraction of plastics was ground using a Rotoplex grinder with a rotation speed of $1500 \mathrm{rpm}$ to obtain fragments with a final size of $6 \mathrm{~mm}$. Each piece was inspected before and after grinding stage. Two successive sorting were only tested for ABS as it is the main polymer found in WEEE. Samples notation is presented in Table 5.

Virgin materials studied are ABS (Toyolac 100MPF, Toray), ABS/PC (Establend 4500, Cossa Polimeri) and HIPS (Escrimo SB, $\mathrm{GmBH}$ ). They were used as reference to compare recycled polymers properties. Indeed, styrene resins ABS, HIPS and ABS/PC copolymers are representative of most of the waste of electrical and electronic equipment for example as the casings of TVs, phones and computer screens. Furthermore, in order to achieve a reliable comparison taking into account the type of WEEE used from styrene resins, raw polymers having a similar degree of injection moulding (MFI between 20 and 23) have been used. On the other hand, the mass composition of terpolymer block ABS and PC/ABS (30-70) is $25 \%$ of acrylonitrile, $25 \%$ of butadiene and $50 \%$ of styrene.

\subsubsection{Sample preparation}

Sorted ABS, HIPS and ABS/PC were processed using a twin screw extruder with a screw length of $900 \mathrm{~mm}$ (L/D = 36, co-rotating, Clextral BC21). Temperature profiles were adapted to recycled plastics: $240^{\circ} \mathrm{C}$ for $\mathrm{ABS} / \mathrm{PC}, 220^{\circ} \mathrm{C}$ for HIPS and $230^{\circ} \mathrm{C}$ for ABS. Granulates were injection moulded with a Sandretto $95 \mathrm{t}$ injection moulding machine to obtain standardized specimens. ABS/PC was dried at $120^{\circ} \mathrm{C}$ for $4 \mathrm{~h}$ before extrusion and injection.

\subsubsection{Mechanical and fire behaviour characterizations}

Tensile tests were performed on dogbones specimens, according to ISO 527-1 standard, using a Zwick Z010 tensile tester. Young's modulus measurements were made at a crosshead speed of $1 \mathrm{~mm} / \mathrm{min}$, and elongation measurements were made at $50 \mathrm{~mm} / \mathrm{min}$. The reported values for all tensile properties are the average of 10 determinations. Impact tests were carried out on according to ISO 179 standard, with a Zwick 5102 Charpy pendulum impact tester. Only ABS/PC specimens were notched. Indeed, tests performed on unnotched ABS/PC specimens led to values outside the energy range of the pendulum (7.5 J). Impact results are the average of tests run with 15 specimens.

Fire reaction properties of the samples were studied using UL $94 \mathrm{~V}$ fire test and Glow Wire Ignition Test (GWIT) according to IEC 60695-2-12. The tests were respectively carried out on $12.5 \mathrm{~mm} \times 12.5 \mathrm{~mm} \times 3.2 \mathrm{~mm}$ injection moulded barrels and $50 \mathrm{~mm} \times 50 \mathrm{~mm} \times 4 \mathrm{~mm}$ injection moulded square sheets. We report the GWIT maximum temperature of each sample after three consecutive tests for the same composition.

\section{Results and discussion}

\subsection{Sorting performances}

The purity and removal efficiency obtained for ABS, HIPS and ABS/PC sorted with NIR sorting devices are presented on Fig. 2 and 

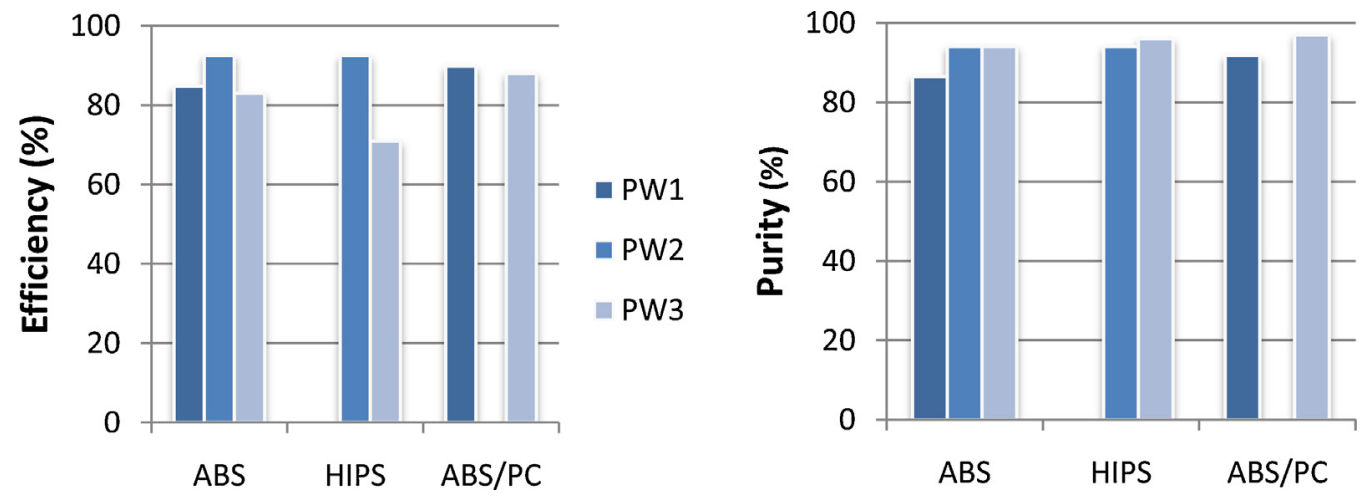

Fig. 2. Sorting performances of the device 2 with database B.

Table 6. With device 1, efficiency is at $80 \%$ for all the studied polymers. Purities of HIPS and ABS are at $70 \%$, while ABS/PC is at $85 \%$. The presence of PC helps in detecting the ABS/PC which leads to a higher purity for $A B S / P C$, while the distinction between $A B S$ and HIPS was not successful. With device 2, PW2, which only contains pieces with sizes higher than $20 \mathrm{~mm}$, presents the best results of removal efficiency (>90\%). Except for HIPS from PW3, all efficiencies obtained were higher than $80 \%$. This result can be explained by the low concentration of HIPS in PW3 (2.6wt\%). PW1, only constituted of $\mathrm{ABS}$ and $\mathrm{ABS} / \mathrm{PC}$, displays rather poor purity results.
ABS
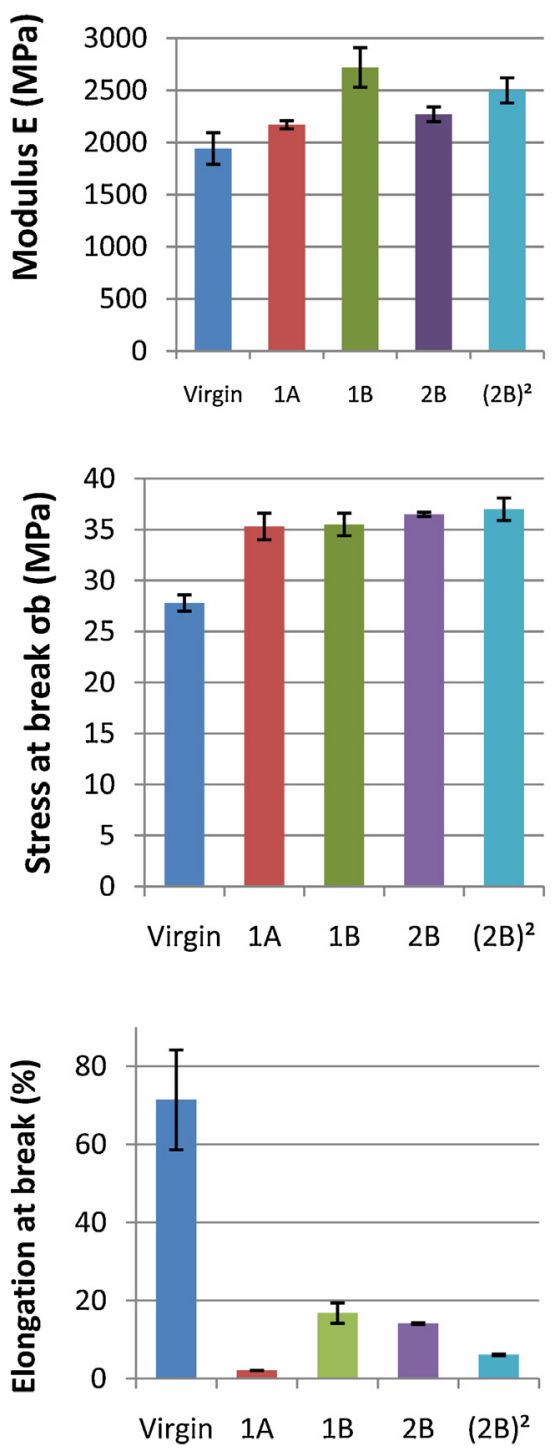

ABS/PC
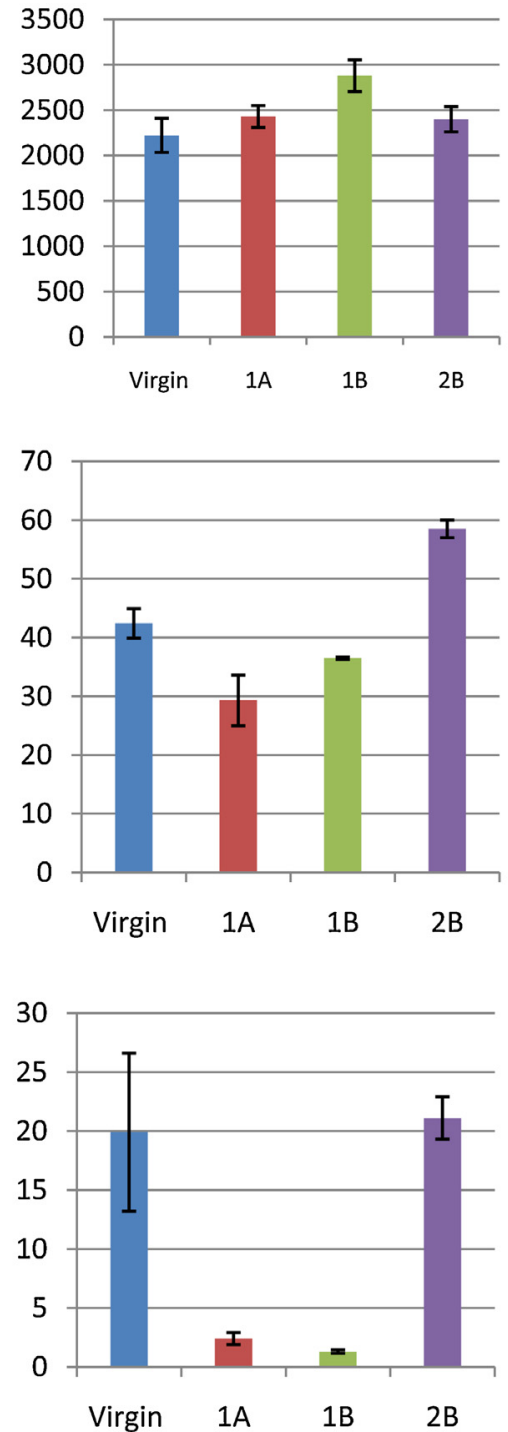

HIPS
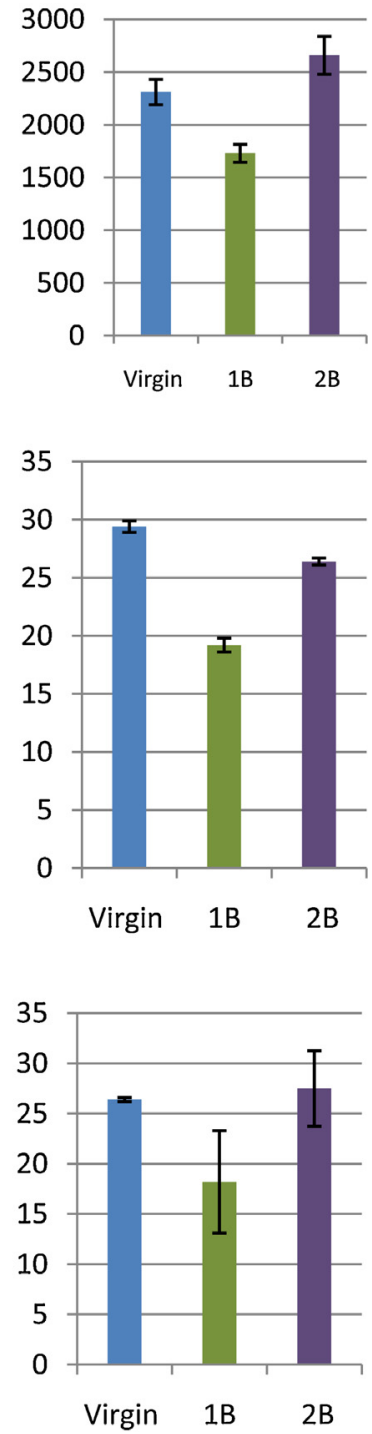

Fig. 3. Mechanical properties of sorted ABS, ABS/PC and HIPS (error bars represent one standard deviation). 
Table 6

Sorting performances of device 1 .

\begin{tabular}{lccc}
\hline & ABS & HIPS & ABS/PC \\
\hline Purity & $70 \%$ & $70 \%$ & $85 \%$ \\
Efficiency & $80 \%$ & $80 \%$ & $80 \%$ \\
\hline
\end{tabular}

This can be ascribed to the difficulty in distinguishing ABS/PC from ABS. Purity obtained with actual WEEE deposits, PW2 and PW3, were higher than $90 \%$. Other sorting technologies in development lead to the same performances. Indeed, results of purity for ABS and HIPS are similar to the performances obtained recently by Hui et al., with a dissolved air flotation sorting method in two stages, by using specific wetting agents (Hui et al., 2012). A purity of around $50 \%$ for $A B S$ in a binary mixture of $A B S / P S$ was obtained using a triboelectrostatic separation process (Dodbiba et al., 2005). Separation of ABS and HIPS was carried out using froth flotation with the use of selected wetting agents (Pascoe, 2005); however no tests were performed on actual deposit of WEEE mixed plastics.

Improved NIR-based sorting process leads to purities higher than $90 \%$ for all sorted polymers and enables to separate polymers of the same family of styrenic.

\subsection{Mechanical properties}

\subsubsection{Tensile properties}

As expected, tensile properties of the three recycled polymers are notably different from the reference polymers (Fig. 3). For ABS and $\mathrm{ABS} / \mathrm{PC}$, elongation at break decreases drastically while modulus is quite similar or higher than virgin one. Stress at break increases for $A B S$, but not for $A B S / P C$, for which the results depends on sorting process. $2 \mathrm{~B}$ leads to the best tensile properties for $\mathrm{ABS} / \mathrm{PC}$. Conversely, no specific trend is observed regarding the sorting process used for ABS: elongation at break decreases, while other properties increase in comparison with virgin ABS. With a second sorting $\left(2 \mathrm{~B}^{2}\right)$, mechanical properties are close as with only one sorting (2B).

Recycled HIPS 1B has lower tensile properties than virgin HIPS. Sorting process $2 \mathrm{~B}$ allows tensile modulus and elongation at break to be improved.

3.2.1.1. Discussion about tensile properties of ABS. Few studies about recycling of styrenic polymers have been made using postconsumer materials (Arnold et al., 2010; Brennan et al., 2002; Barthes et al., 2011). Most of times, virgin polymers are reprocessed to simulate recycling loops (Pérez et al., 2010; Vilaplana et al., 2006). This leads to only take into account melt processing degradation on mechanical properties, without considering the influence of impurities and ageing phenomena, occurring during the useful life of end-of-life products. In the case of post-consumer materials, impurities resulting from automatic or manual sorting and ageing of polymers can lead to a slight diminution of molecular weight (Scaffaro et al., 2012).

Generally for ABS, similar trends are observed: tensile strength and modulus are slightly modified, whereas elongation at break considerably decreases (Bai et al., 2007; Karahaliou and Tarantili, 2009; Brennan et al., 2002; Salari and Ranjbar, 2008). One can note that elongation at break of virgin ABS can vary between $20 \%$ and $70 \%$ depending on the grade used and thus the PB loading. The important decrease of elongation at break is often ascribed to the $\mathrm{PB}$ degradation as well as to the mix of various grades of ABS.

Loss of mechanical properties during recycling can be explained by several phenomena. Bai et al. suggest that the loss of small volatiles molecules during processing, as lubricants for instance, induces a loss of mechanical properties (Bai et al., 2007). Increase of tensile strength and Young's modulus can be explained by

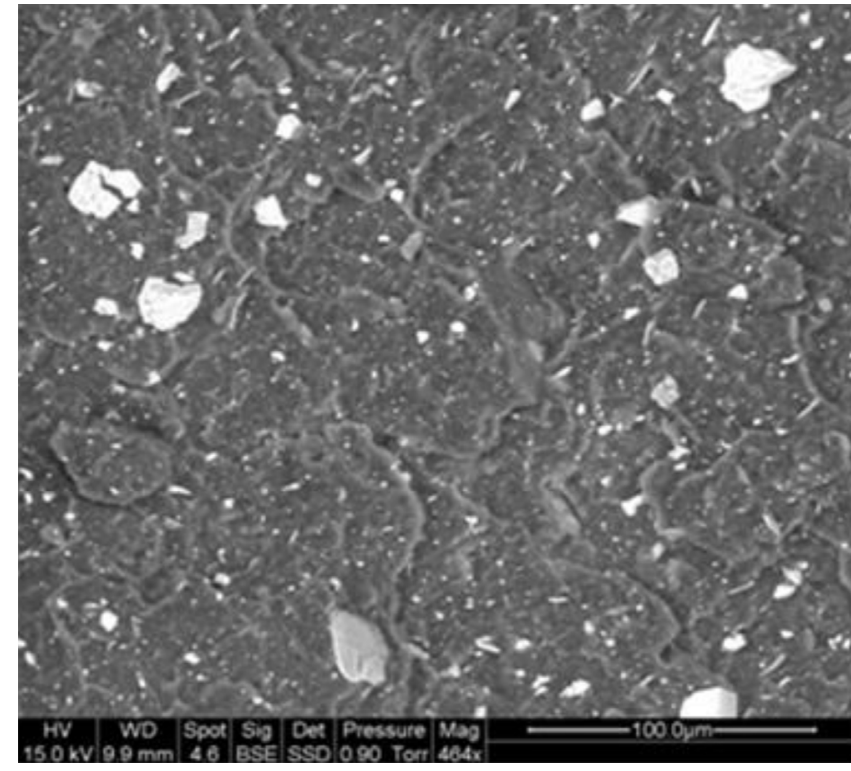

Fig. 4. SEM micrograph of fracture surface of ABS after tensile test.

the presence of impurities and especially $A B S / P C$. In the case of the model lot PW1, it can be noticed that after sorting ABS contains around $15 \mathrm{wt} \%$ of ABS/PC. The presence of impurities was confirmed on the SEM micrograph of the fracture surface of ABS after tensile test (Fig. 4), the nature of impurities was determined by X-ray analysis: calcite and clay on this sample.

Tarantili et al., observed that the incorporation of PC into ABS leads to an increase of tensile strength and elasticity modulus, as predicted by the law of mixtures. The degradation of polymeric phases, as polybutadiene and/or SAN, causes chain-scission or crosslinking, leading to the formation of oxidized moieties (Scaffaro et al., 2012; Salari and Ranjbar, 2008). Karahaliou studied ABS thermomechanical degradation by Fourier transform infrared spectroscopy (FTIR) on virgin ABS reprocessed five times: hydroxyl and ester peaks intensities increased with the number of extrusion cycles (Karahaliou and Tarantili, 2009). It was suggested that crosslinking reactions could be predominant since tensile strength and Young's modulus increased notably, thanks to the network formation (Karahaliou and Tarantili, 2009).

Whatever the conditions of sorting, elongation at break of recycled materials is always significantly lower than the virgin ones. As for other tensile properties, the degradation of the butadiene rubber phase and the loss of small molecules (monomers, thermal stabilizers, functional molecules, etc.) are the explanations generally proposed. The results obtained, showing an increase in the modulus of elasticity compared with the reference ABS seems to confirm these explanations. Polybutadiene phase degradation was confirmed by IR spectroscopy made on the Bruker IFS 66 FTIR spectrophotometer, sorted ABS from WEEE was compared to virgin $\mathrm{ABS}$ and virgin styrene-acrylonitrile polymer (SAN) (Fig. 5). The characteristic bands of carbon double bonds around $900 \mathrm{~cm}^{-1}$ drastically decrease for sorted ABS from WEEE, this zone is more similar than the spectrum obtained with SAN polymer, which does not contain polybutadiene phase. Other interpretations are related to both the presence of impurities, which facilitates the initiations and propagations of cracks, and microstructure modifications of $A B S$. The improvement of the impact strength by further sorting could confirm the negative role of the impurities about the ultimate properties.

3.2.1.2. Discussion about tensile properties of $A B S / P C$. Mechanical properties of the different sorted $A B S / P C$ are greatly influenced by 


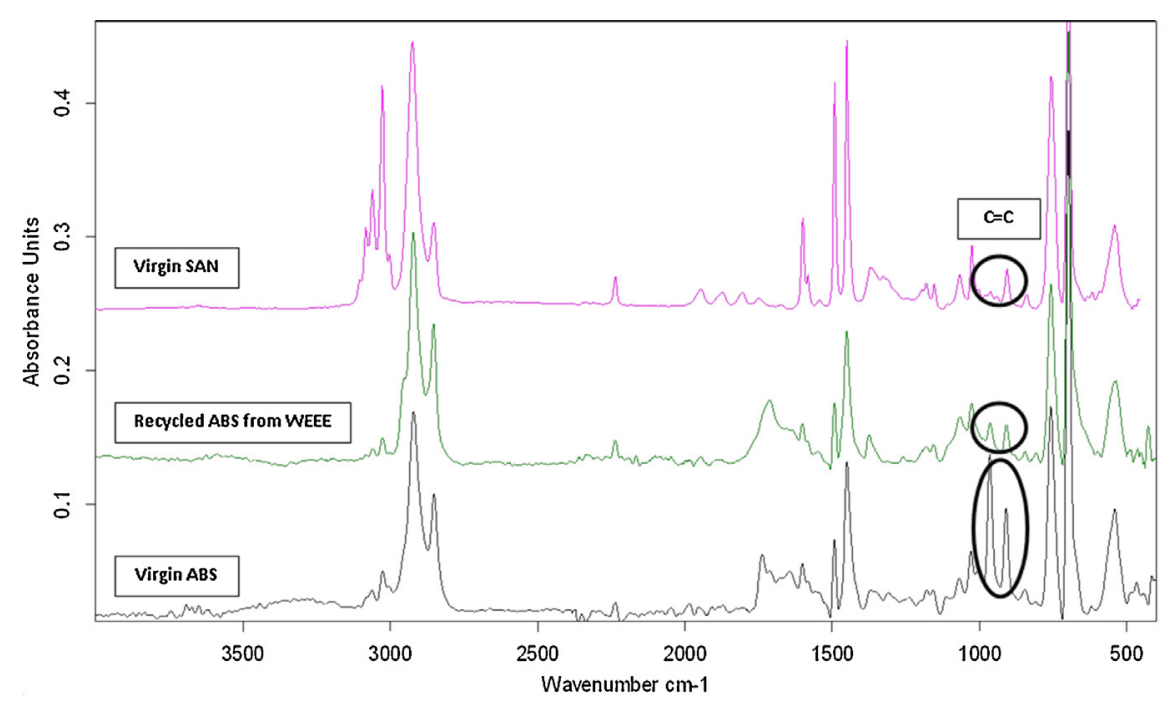

Fig. 5. NIR spectra of virgin ABS, recycled ABS from WEEE and virgin SAN.

the presence of impurities. Using process $1 \mathrm{~A}$ or $1 \mathrm{~B}$, a significant decrease in elongation at break is observed. $A B S / P C$ elongation at break for $2 \mathrm{~B}$ process is at the same level as virgin polymer blend. $A B S / P C$ properties depend on the amount of each monomer in the ABS terpolymer (Inberg, 2001) as well as the ABS/PC ratio. Moreover, $\mathrm{ABS}$ is generally the minor phase in the ABS/PC blend, thus the polybutadiene degradation phase is less notable than for pure ABS. Studies on PC reprocessing have shown that tensile properties are, in most of cases, few affected by the first cycles of processing (Pérez et al., 2010; Aguirre Flores and Sanchez-Valdes, 1999). However, Eguiazabal and Nazabal observed that tensile strength and elongation at break of ABS/PC began to decrease after the third cycle of reprocessing and ascribed it to a large degradation of butadiene rubber phase (Eguiazabal and Nazabal, 1990).

Since high levels of mechanical properties are reached for $\mathrm{ABS} / \mathrm{PC} 2 \mathrm{~B}$ thanks to high purity, it could be expected that a second sorting step $\left(2 \mathrm{~B}^{2}\right)$ could entail better mechanical properties, due to a higher purity of $\mathrm{ABS} / \mathrm{PC}$. It will be confirmed by further works.

3.2.1.3. Discussion about tensile properties of HIPS. HIPS was only sorted with the database B (Fig. 3). Device 1 has lower sorting performances, which is confirmed by the mechanical properties of HIPS 1B. The presence of a minor phase of others polymers, such as PE and PP polyolefins, induces a decrease of tensile properties. Without the use of compatibilizers, adhesion between polyolefins and styrenic polymers is weak (Santana and Manrich, 2002; Horák et al., 1996). Moreover, polystyrene matrix displays a good resistance to degradation for the first reprocessing cycles (Remili et al., 2011). Because of the lower content of PB in HIPS than in ABS (10 wt\% often used in HIPS vs whereas $10-25 \mathrm{wt} \%$ often used in ABS), tensile properties of HIPS are less affected by recycling. Studies about influence of reprocessing on tensile properties of HIPS present various results and conclusions. For Brennan et al., reprocessing cycles do not have noticeable effects on the tensile strength and elastic modulus of HIPS, whereas Santana et al. observed a notable decrease in the tensile properties (Brennan et al., 2002; Santana and Manrich, 2002). Vilaplana et al. also observed a weak influence of first reprocessing cycle on tensile properties of recycled HIPS (Vilaplana et al., 2006). Nevertheless, influence of reprocessing on tensile properties is rarely noticeable after the first re-extrusion cycle, but thermochemical ageing must also be considered (Vilaplana et al., 2011). Influence of processing parameters is also not negligible, but cannot be compared for the above publications. The results of Fig. 3 highlight the improvement of the mechanical properties thanks to the improvement of the NIR sensitivity, and thus of its resolution. The reduction of the stress at break of HIPS 2B compared with virgin HIPS can be explained by the presence of impurities having a higher modulus of elasticity (probably ABS), but also leading to microstructure modifications. Nevertheless, tensile properties of HIPS using 2B process are very close to virgin HIPS ones. Consequently, a good sorting of HIPS in a real WEEE deposit can be expected.

\subsubsection{Impact properties}

Most of studies about recycling of styrenic blends have concluded that impact properties are the most affected by recycling and should be decisive for the use of recycled polymers in many applications requiring minimum values of impact strength. Impact properties of sorted polymers are presented on Fig. 6 .

Device 1 always leads to a reduction of the impact strength, except for ABS 1B. This can be mainly ascribed to a high content of impurities, such as polyolefins, as they present poor interfacial interactions with the matrix. As device 1 has weak sorting performances, distinction of ABS and HIPS polymers should not be done. Thus, the increase in impact strength noticed for ABS $1 \mathrm{~B}$ in comparison with all sorted $A B S$ could be explained by the presence of a small fraction of HIPS which exhibits higher values of this property as in the case of our reference materials. This minor fraction of HIPS could also present a less degraded polybutadiene fraction.

With $2 B$ sorting, ABS and ABS/PC are more affected than HIPS which exhibits impact strength close to virgin HIPS one. Impact resistances of $A B S$ and $A B S / P C$ are ruled by the polybutadiene phase, while SAN polymer presents low impact properties. Degradation of the $\mathrm{PB}$ phase, occurring during reprocessing and ageing, leads naturally to a reduction of the $A B S$ and $A B S / P C$ fracture energy. Grafting presents on $\mathrm{PB}$ phase should be degraded, leading to an agglomeration of the PB particles and then to a reduction of the toughness of ABS (Xu et al., 2005). Moreover, the presence of impurities in ABS and $A B S / P C$ could modify the blend microstructure, entailing also an agglomeration of $\mathrm{PB}$ particles.

As well as for the tensile properties of $A B S$, the presence of $\mathrm{ABS} / \mathrm{PC}$ could decrease the impact properties of ABS. Barthes et al., studied the incorporation of $\mathrm{PC}$ into ABS and observed that even at low PC content, impact properties of ABS were significantly affected (Barthes et al., 2011).

Luzuriaga et al. studied the influence of thermochemical ageing and reprocessing on HIPS properties; they showed that impact 

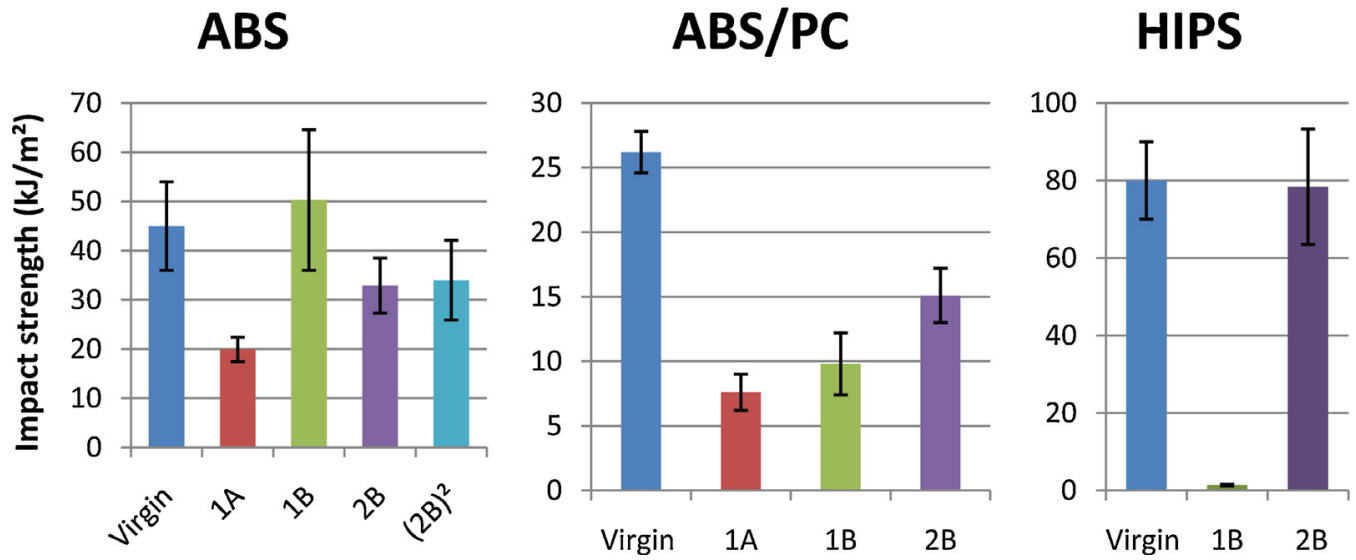

Fig. 6. Impact properties of sorted ABS, ABS/PC and HIPS (error bars represent one standard deviation).

strength of HIPS submitted to photochemical ageing decreased because of a surface degradation, whereas reprocessing led to a recovery of the initial impact strength thanks to the mixing at molten state of the material (Luzuriaga et al., 2006). Repeated extrusion had no clear effect on HIPS impact properties (Santana and Manrich, 2002), certainly because of the high thermal stability of PS and the low PB loading.

Finally, it appears that the increase of purity achieved with the $2 \mathrm{~B}$ process leads to restored impact properties for HIPS. For ABS and $A B S / P C$, impact strength is reduced; however, those recycled materials can still be convenient for many applications

\subsection{Fire reaction tests}

Flame retardants are present in $30 \%$ of plastics of EEE (Vehlow et al., 2003). Brominated flame retardants (BFR) are generally used with styrenic polymers, and particularly for HIPS and ABS which present lower limiting oxygen index values than $A B S / P C$ and $P C$ due to the auto-extinguishing ability of PC. Fire reaction tests were performed for HIPS and ABS sorted with process $2 B$, in order to confirm the presence of FR additives since brominated flame retardants have been identified using X-ray diffraction on plastic parts, prior to grinding stages. Results showed that the recycled polymers are classified favourably (Table 7). (2B) ${ }^{2}$ process for ABS even exhibits a high level of fire performance, since $\mathrm{V} 0$ is the highest class.

Therefore, the likely presence of several kinds of flame retardants for a same type of polymer does not appear to play a detrimental effect on flame retardancy. Hence, flame retardant compounds could offer complementary effects or even synergistic effects on fire behaviour.

Some of the brominated flame retardants (BFR) present in the samples are possibly restricted of use by the RoHS Directive (European Commission, 2003b). However, as no technology enables to identify automatically the chemical nature of BFR, all brominated plastic waste must be separated from the mechanically recycled plastic stream. NIR technology should be used with a complementary analytic tool, able to identify the presence of brominated FR, as laser induced breakdown spectroscopy (Kaski et al., 2004) or hand

Table 7

Fire behaviour of virgin ${ }^{\mathrm{a}}$ and recycled polymers sorted with process $2 \mathrm{~B}$.

\begin{tabular}{llllll}
\hline & Virgin HIPS & HIPS 2B & Virgin ABS & ABS 2B & ABS (2B) $)^{2}$ \\
\hline UL 94 classification & HB & V1 & HB & V1 & V0 \\
Max GWIT & 650 & 850 & 750 & 850 & 960 \\
temperature $\left({ }^{\circ} \mathrm{C}\right)$ & & & & & \\
\hline
\end{tabular}

a Values of virgin polymers come from technical data sheets. held X-ray fluorescence (XRF) device as it was recently done by Menad et al. (2012).

\section{Conclusion}

Improvement of a NIR sorting device enabled to reach high levels of purity for three of the most used plastics in WEEE: $\mathrm{ABS}, \mathrm{ABS} / \mathrm{PC}$ and HIPS, with impurities content varying between 5 and $8 \%$ in weight. Mechanical properties of materials obtained by reprocessing of the sorted polymers were determined. Recycled HIPS sorted with the improved device and database (2B) presents mechanical properties very close to virgin one. A degradation of the polybutadiene phase of $\mathrm{ABS}$ and $\mathrm{ABS} / \mathrm{PC}$ was observed and confirms various previous works. Hence, elongation at break and impact strength decreased compared to virgin polymers. Despite further improvement of the sorting device is required, substitution ratio of a recycled HIPS sorted by NIR automating technology can be assumed to be 1 in view of the mechanical properties of HIPS 2B. Indeed, mechanical properties of HIPS 2B are closed of those of virgin HIPS, and thus it could be used instead of virgin HIPS, without the addition of virgin HIPS. This result can only be applied to the HIPS from the studied deposit, with this sorting device. For ABS and ABS/PC, complementary studies should be carried out to evaluate it accurately. However, substitution ratios should be quite near of 1 for these polymers, because of the low degradation of mechanical properties. The presence of flame retardants in recycled plastics from WEEE was confirmed by fire reaction tests and X-ray diffraction. NIR technology did not permit to identify these additives; however it can be coupled with X-ray fluorescence device in order to separate brominated polymers from recycled polymers. Obtaining sorted materials with similar performances to reference materials can allow iso-function applications to be envisaged, but also various beneficial applications, leading to ecological and economical gains. Degradation of the visual aspect of recycled polymers is still a concern for reusing them in visible pieces. Future works should be performed on the acceptability of such materials by consumers through the improvement of sensorial properties of these recycled polymers.

\section{Acknowledgments}

The authors are grateful to the PELLENC ST company for its technical support. We also thank ADEME for its financial support.

\section{References}

Aguado J, Serrano DP, San Miguel G. European trends in the feedstock recycling of plastics wastes. Global Wastes NEST Journal 2006;9:9-12. 
Aguirre Flores R, Sanchez-Valdes S. Effect of reprocessing and moisture on the properties of bisphenol-A polycarbonate. Journal of Injection Molding Technology 1999;3:21-6.

Al-Salem SM, Lettieri P, Baeyens J. Recycling and recovery routes of plastic solid waste (PSW): a review. Waste Management 2009;29(10): 2625-43.

Anzano J, Bonilla B, Montull-Ibor B, Casas-González J. Plastic identification and comparison by multivariate techniques with laser-induced breakdown spectroscopy. Journal of Applied Polymer Science 2010;121:2170-6.

Arnold JC, Watson T, Alston S, Carnie M, Glover C. The use of FTIR mapping to assess phase distribution in mixed and recycled WEEE plastics. Polymer Testing 2010;29:459-70

Bai X, Isaac DH, Smith K. Reprocessing acrylonitrile-butadiene-styrene plastics: structure-property relationships. Polymer Engineering and Science 2007:47(2):120-30.

Barthes ML, Mantaux O, Pedros M, Lacoste E, Dumon M. Recycling of aged abs from real WEEE through $\mathrm{ABS} / \mathrm{PC}$ blends in the abs-rich compositions. Advances in Polymer Technology 2011:1-11.

Bledzki AK, Nowaczek W. Identification of plastics in waste materials and methods for their recycling. International Polymer Science and Technology 1994;21:73-80.

Boeykens S, Vázquez C. Preliminary classification of polymers by using total-reflection X-ray fluorescence spectra. Spectrochimica Acta Part B 2004:59(8):1189-92.

Brennan LB, Isaac DH, Arnold JC. Recycling of acrylonitrile-butadiene-styrene and high-impact polystyrene from waste computer equipment. Journal of Applied Polymer Science 2002;86:572-8.

Buchan R, Yarar B. Recovery plastics for recycling by mineral processing techniques. JOM 1995:47:52-5.

Bucknall CB, Frederic FP, Cote FFP, Partridge IK. Effects of rubber particle volume fraction on deformation and fracture in HIPS. Journal of Materials Science 1986;21:301-6.

Dodbiba G, Sadaki J, Okaya K, Shibayama A, Fujita T. The use of air tabling and triboelectric separation for separating a mixture of three plastics. Minerals Engineering 2005;18(15):1350-60.

Ebert J, Bahadir M. Formation of PBDD/F from flame-retarded plastic materials under thermal stress. Environment International 2003:29:711-6.

Eguiazabal JI, Nazabal J. Reprocessing polycarbonate/acrylonitrile-butadienestyrene blends: influence on physical properties. Polymer Engineering and Science 1990;30:527-31

Elmaghor F, Zhang L, Fan R, Li H. Recycling of polycarbonate by blending with maleic anhydride grafted ABS. Polymer 2004;45(19):6719-24.

European Commission. Directive 2002/95/EC of the European Parliament and of the Council on the restriction of the use of certain hazardous substances in electrical and electronic equipment. Official Journal of the European Union 2003a;37:19-23.

European Commission. Directive 2002/96/EC of the European Parliament and of the Council of 27 January 2003 on waste electrical and electronic equipment (WEEE). Official Journal of the European Union 2003b;37:24-38.

Ferrara G, Meloy TP. Low dense media process: a new process for low-density solid separation. Powder Technology 1999;103:151-5.

Finnveden G, Johansson J, Lind P, Moberg A. Life cycle assessment of energy from solid waste - part 1: general methodology and results. Journal of Cleaner Production 2005;13(3):213-29.

Florestan J, Lachambre A, Mermilliod N, Boulou JC, Marfisi C. Recycling of plastics: automatic identification of polymers by spectroscopic methods. Resources, Conservation and Recycling 1994:10(1/2):67-74.

Frees N. Miljømæssige fordele og ulemper ved genvinding af plast [Environmental advantages and disadvantages the recycling of plastics examples based on specific products]. In: Danish Environmental Protection Agency, Environmental report no. 657, Copenhagen, Denmark; 2002.

Garforth A, Salmiaton A, Hernandez-Martınez J, Akah A. Feedstock recycling of polymer wastes. Current Opinion in Solid State and Materials Science 2004;8(6):419-25

Horák Z, Fořt V, Hlavatá D, Lednický F, Večerka F. Compatibilization of high-impact polystyrene/polypropylene blends. Polymer 1996:37(1):65-73.

Hosoda E. International aspects of recycling of electrical and electronic equipment: material circulation in the East Asian region. Journal of Material Cycles and Waste Management 2007;9(2):140-50.

Hui W, Xiao-lei C, Yang B, Chao G, Zhang L. Application of dissolved air flotation on separation of waste plastics ABS and PS. Waste Management 2012;32(7):1297-305

Huisman J, Magalini F, Kuehr R, Maurer C, Delgado C, Artim E, Szlezak J, Stevels AB, Ogilvie S, Poll J. 2008 Review of Directive 2002/96 on Waste Electrical and Electronic Equipment (WEEE) (Final Report). United Nations University Study No. 07010401/2006/442493/ETU/G4, Bonn, Germany; 2007.

Huth-Fehre Th, Feldhoff R, Kantimm Th Quick L, Winter F, Cammann K, Van den Broek W, Wienke D, Melssen W, Buydens L. NIR-remote sensing and artificial neural networks for rapid identification of post-consumer plastics. Journal of Molecular Structure 1995;348:143-6.

Inberg JPF. Fracture of polycarbonate/ABS blends. Enschede, the Netherlands: University of Twente; 2001 [Thesis]

ISO 14040. Environmental Management. Life Cycle Assessment. Principles and Framework; 2006

Jenseit W, Stahl H, Wollny V. Recovery options for plastic parts from end-of-life vehicles: an eco-efficiency assessment. Darmstadt: Öko-Institut eV; 2003.
Karahaliou EK, Tarantili PA. Stability of ABS compounds subjected to repeated cycles of extrusion processing. Polymer Engineering and Science 2009;49(11):2269-75.

Karstang TV, Henriksen A. Infrared spectroscopy and multivariate calibration used in quantitative analysis of additives in high-density polyethylene. Chemometrics and Intelligent Laboratory Systems 1992;14(1-3):331-9.

Kaski S, Häkkänen $\mathrm{H}$, Korppi-Tommola J. Determination of $\mathrm{Cl} / \mathrm{C}$ and $\mathrm{Br} / \mathrm{C}$ ratios in pure organic solids using laser-induced plasma spectroscopy in near vacuum ultraviolet. Journal of Analytical Atomic Spectrometry 2004;19:474-8.

Lazarevic D, Aoustina E, Buclet N, Brandt N. Plastic waste management in the context of a European recycling society: comparing results and uncertainties in a life cycle perspective. Resources, Conservation and Recycling 2010;55: 246-59.

Luederwald I. Mass spectroscopy of synthetic polymers. Pure and Applied Chemistry 1981;54(2):255-65.

Luzuriaga S, Kovarova J, Fortelny I. Degradation of pre-aged polymers exposed to simulated recycling: properties and thermal stability. Polymer Degradation and Stability 2006;91:1226-32

Mailhot B, Gardette J. Fourier transform infrared and Fourier transform Raman analysis of styrenic polymers. Vibrational Spectroscopy 1996;1:69-78.

Mehat NM, Kamaruddin S. Optimization of mechanical properties of recycled plastic products via optimal processing parameters using the Taguchi method. Journal of Materials Processing Technology 2011;211(12):1989-94.

Menad N, Blorkman B, Allain EG. Combustion of plastics contained in electric electronic scrap. Resources, Conservation and Recycling 1998;24:65-85.

Menad N, Guignot S, Van Houwelingen JA. New characterisation method of electrical and electronic equipment wastes (WEEE). Waste Management 2012. http://dx.doi.org/10.1016/j.wasman.2012.04.007

Mirza R. A review of the role of plastics in energy recovery. Chemosphere 1999;38(1):207-31

Pascoe RD. The use of selective depressants for the separation of ABS and HIPS by froth flotation. Minerals Engineering 2005;18:233-7.

Pérez JM, Vilas JL, Laza JM, Arnáiz S, Mijangos F, Bilbao E, Rodríguez M. Effect of reprocessing and accelerated ageing on thermal and mechanical polycarbonate properties. Journal of Materials Processing Technology 2010;210(5):727-33.

Perrin D, Guillermain C, Bergeret A, Lopez-Cuesta JM, Tersac G. SMC composites waste management as reinforcing fillers in polypropylene by combination of mechanical and chemical recycling processes. Journal of Materials Science 2006:41:3593-602.

Perugini F, Mastellone ML, Arena U. A life cycle assessment of mechanical and feedstock recycling options for management of plastic packaging wastes. Environmental Progress 2005;24:137-54.

Pongstabodee S, Kunachitpimol N, Damronglerd S. Combination of three-stage sinkfloat method and selective flotation technique for separation of mixed postconsumer plastic waste. Waste Management 2007;28:475-83

Puckett J, Byster L, Westervelt S, Gutierrez R, Davis S, Hussain A, Dutta M. Exporting Harm The High-Tech Trashing of Asia. Basel Action Network and Silicon Valley Toxics Coalition; 2003, Available from: http://www.ban.org/E-waste/technotrashfinalcomp.pdf

Remili C, Kaci M, Benhamida A, Bruzaud S, Grohens Y. The effects of reprocessing cycles on the structure and properties of polystyrene/Cloisite $15 \mathrm{~A}$ nanocomposites. Polymer Degradation and Stability 2011:96:1489-96.

Salari D, Ranjbar H. Study on the recycling of ABS resins: simulation of reprocessing and thermo-oxidation. Iranian Polymer Journal 2008;17(8):599-610.

Santana RM, Manrich S. Studies on morphology and mechanical properties of $\mathrm{PP} / \mathrm{HIPS}$ blends from postconsumer plastic waste. Journal of Applied Polymer Science 2002:87:747-51.

Scaffaro R, Botta L, Di Benedetto G. Physical properties of virgin-recycled ABS blends: effect of post-consumer content and of reprocessing cycles. European Polymer Journal 2012;48:637-48.

Scott D, Waterland R. Identification of plastic waste using spectroscopy and neural networks. Polymer Engineering and Science 1995;35(12):1011-25

Secretariat of the Basel Convention (SBC). Where are WEee in Africa? Findings from the Basel Convention E-waste Africa Programme. Châtelaine, Switzerland: Secretariat of the Basel Convention; 2011.

Serranti S, Gargiulo A, Bonifazi G. Classification of polyolefins from building and construction waste using NIR hyperspectral imaging system. Resources, Conservation and Recycling 2012;61:52-8

Shen H, Pugh R, Forssberg E. Floatability, selectivity and flotation separation of plastics by using a surfactant. Colloids and Surfaces A 2002;196:63-70.

Shibata J, Matsumoto S, Yamamoto H, Kusaka E. Pradip flotation separation of plastics using selective depressants. International Journal of Mineral Processing 1996;48:127-34

Shonfield P. LCA of management options for mixed waste plastic. London: WRAP Waste Resource Action Programme; 2008.

Solera P, Nirsberger M, Castillo N. Measuring stabilizers in pigmented plastics with near-infrared spectroscopy. Coloring Technology for Plastics 1999:197-207.

Taurino R, Pozzi P, Zanasi T. Facile characterization of polymer fractions from waste electrical and electronic equipment (WEEE) for mechanical recycling. Waste Management 2010;30:2601-7.

Ulrici A, Serranti S, Ferrari C, Cesare D, Foca G, Bonifazi G. Efficient chemometrics strategies for PET-PLA discrimination in recycling plants using hyperspectral imaging. Chemometrics and Intelligent Laboratory Systems 2013;122:31-9.

United Nation Environment Program (UNEP). Sustainable Innovation and Technology Transfer Industrial Sector Studies: Recycling - From E-waste to resources, Final Report; 2009. 
Van den Broek W, Wienke D, Melssen WJ, Buydens L. Plastic material identification with spectroscopic near infrared imaging and artificial neural networks. Analytica Chimica Acta 1998;361:161-76.

Vehlow J, Bergfeldt B, Hunsinger H, Seifert H, Mark FE. Bromine in waste incineration: partitioning and influence on metal volatilisation. Environmental Science and Pollution Research International 2003;10(5):329-34

Vilaplana F, Karlsson S, Ribes-Greus A, Schade C, Nestle N. NMR relaxation reveals modifications in rubber phase dynamics during long-term degradation of highimpact polystyrene (HIPS). Polymer 2011;52:1410-6.

Vilaplana F, Karlsson S. Quality concepts for the improved use of recycled polymeric materials: a review. Macromolecular Materials and Engineering 2008;293:274-97.
Vilaplana F, Ribes-Greus A, Karlsson S. Degradation of recycled high-impact polystyrene. Simulation by reprocessing and thermo-oxidation. Polymer Degradation and Stability 2006;91:2163-70.

Wahab D, Hussain A, Scavino E, Mustafa M, Basri H. Development of a prototype automated sorting system for plastic recycling. American Journal of Applied Sciences 2006;3(7):1924-8

Weyer LG. Near-infrared spectroscopy of organic substances. Applied Spectroscopy Reviews 1985;21(1/2):1-43.

Xu XF, Wang R, Tan ZY, Yang HD, Zhang MY, Zhang HX. Effects of polybutadieneg-SAN impact modifiers on the morphology and mechanical behaviours of ABS blends. European Polymer Journal 2005;41:1919-26. 